\title{
Reproductive and sexual health in women with bipolar disorder: a comparative study
}

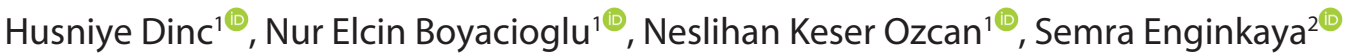 \\ ${ }^{1}$ Istanbul University, Cerrahpasa Faculty of Health Sciences, Department of Midwifery, Istanbul - Turkey \\ ${ }^{2}$ Bakirkoy Training and Research Hospital for Psychiatry Neurology and Neurosurgery, Department of Psychiatry, Istanbul - Turkey
}

\begin{abstract}
Objective: The aim of this study was to determine the reproductive and sexual health problems of female patients with bipolar disorder.

Method: This cross-sectional descriptive and comparative study was conducted with 358 female patients with bipolar disorder and a healthy control group $(n=346)$. Data were collected through face-to-face interviews and a questionnaire, which was prepared by the researchers based on the literature and designed to determine the reproductive and sexual health issues among the participants.

Results: It was determined that the bipolar disorder group had no previous knowledge about menarche and did not menstruate regularly. Compared to the healthy controls, they also experienced more premenstrual problems, masturbated more, had more sexual partners and had more sexually transmitted diseases. Unplanned pregnancy and abortion rates reported more in bipolar group. Moreover, bipolar disorder group reported not to have mammograms and gynecological examinations as required.

Conclusion: Our findings suggest that female patients with bipolar disorder had more reproductive and sexual health related problems than those healthy controls.
\end{abstract}

Keywords: Bipolar disorder, family planning services, reproductive health, sexuality.

\section{INTRODUCTION}

Bipolar disorder (BD) is an important mental illness with a lifetime prevalence of above $1 \%$, starting in young adulthood and progressing with acute episodes; it is frequently accompanied by comorbidities. According to data from the World Health Organization (WHO), BD is the sixth-most common cause of disability among all diseases. Its effects may continue beyond the acute episodes during remission, too. Deterioration may be observed in the functionality of patients' psychosocial, marital, professional, and interpersonal as well as reproductive and sexual lives $(1,2)$.

Although there is no significant difference between the sexes in terms of the prevalence rates for $\mathrm{BD}$, it can be said that the course of the disorder is more problematic in women. $\mathrm{BD}$ requires the lifelong use of protective medications; it starts in an early period of life and is of a recurrent nature. However, long-term drug use entails high risks especially for female patients $(1,2)$. BD sufferers may be more prone to certain psychiatric disorders that lead to changes in their hormone status during their

How to cite this article: Dinc H, Boyacioglu NE, Keser Ozcan N, Enginkaya S. Reproductive and Sexual Health in Women with Bipolar Disorder: A Comparative Study. Dusunen Adam The Journal of Psychiatry and Neurological Sciences 2019;32:23-32.

Correspondence: Nur Elcin Boyacioglu, Istanbul University-Cerrahpasa Faculty of Health Sciences Department of Midwifery Demirkapi Caddesi, Karabal Sokak, Bakirköy Ruh ve Sinir Hastalıkları Hastanesi Bahcesi ici 34740 Bakirkoy, Istanbul, Turkey

Phone: +90 212-660-1125/40136 E-mail: bdrgl_nr@hotmail.com

Received: September 03, 2018; Revised: October 10, 2018; Accepted: November 15, 2018 
reproductive period. Furthermore, during pregnancy and in the postpartum period the use of protective medications is frequently interrupted, which constitutes a risk for the recurrence of the disorder. Women with $\mathrm{BD}$ refrain from becoming pregnant and may postpone their pregnancy as a result of the protective treatment they use, or their pregnancy may be terminated due to the teratogenic effect of the medications used during that period. Moreover, menstrual disorders frequently accompanying drug use may affect their fertility (1-3). Cases that show a parallelism between the mood cycle and the menstrual cycle are mentioned in the literature $(3,4)$. There are also indications that the reproductive and sexual health of women with BD may be poor. Among women with $\mathrm{BD}$ the rate of unplanned pregnancy is high (5), as is the rate of sexually transmitted diseases (STDs) $(5,6)$. Morevover, the use of contraceptives is low $(7,8)$ and menstrual problems are more common in this population $(9,10)$. The number of studies on this subject in the Turkish literature is quite insufficient; hence, we aimed to increase the existing knowledge. Our study was planned in order to reveal reproductive and sexual health problems of women with BD by comparing them with healthy women. While clinicians focus on the treatment of patients with psychiatric disorders, other problems (such as physical diseases, reproductive and sexual health problems) are often neglected. This study emphasizes the necessity of considering physical and mental health together. The research questions are as follows:

What reproductive and sexual health problems do women with $\mathrm{BD}$ suffer from?

Is there a difference in the reproductive and sexual health outcomes between women with $\mathrm{BD}$ and the control group?

\section{METHOD}

We designed a cross-sectional, descriptive comparative study that was carried out between February 2016 and February 2017. The patient group consisted of 358 women with $\mathrm{BD}$ receiving treatment in the acute women's inpatient unit of a hospital for mental health and disorders in Istanbul. The average number of $\mathrm{BD}$ patients hospitalized in the last year was 400. Nine participants refused to participate in the study; 8 participants were excluded because they were unable to complete the forms; 3 participants did not know the Turkish language; the response rate was $89.5 \%$. The control group consisted of 346 women who presented to a primary care health institution. The average number of outpatients in the last year at this primary care health institution was 10,000 . As the researcher who collected the data of the control group (NEB) was working outside the institution, only 420 participants were reached. Thirty-five participants refused to participate in the study; 9 participants were excluded because they could not complete the forms; the response rate was $82.4 \%$.

\section{Inclusion criteria}

The patient group included women who

- Had a diagnosis of BD according to the criteria of the Diagnostic and Statistical Manual of Mental Disorders, 5th edition (DSM-5) and were treated at the acute psychiatric clinic, being at a stage close to being discharged (one to two days before leaving the institution),

- Had a history of at least 5 years of BD, as the study aims to investigate the long-term effect of the disorder,

- Were between 18 and 59 years of age,

- Were able to understand the questions and make statements, and expressed their willingness to participate in the study.

The healthy group included women who

- were between 18 and 59 years old,

- had no psychiatric disorders (no scale was used to test for psychiatric diseases; judgment was only based on the participants' self-report in this study)

- presented to a primary care health institution with non-severe physical disorders (such as upper respiratory tract infection, urinary infection, etc.)

\section{Measures}

Data were collected with a 52-item 'Questionnaire on Determining Problems in Reproductive and Sexual Health.' As there is no psychometrically standardized scale in use for that purpose, this questionnaire was prepared based on the literature and experts' views. The data collection form consisted of five parts. These five parts included questions about the participants' sociodemographic characteristics (6 questions), marriage (4 questions), menarche and sexuality (22 questions), family planning and contraception (3 questions), pregnancy and maternal characteristics (8 questions), and gynecological characteristics (9 questions). Each of the questions in the questionnaire was answered in multiple-choice format.

The Information Form was validated through expert opinions. The Expert Board consisted of a psychiatric nurse, a psychiatrist, a psychologist, and an academic member of staff. The Content Validity Index (CVI) was 0.96 .

A pilot study was conducted with 9 women with BD and 9 healthy women who did not participate in the 
study. The questionnaires were finalized according to expert opinions and the results of the pilot practice.

\section{Procedure}

The prospective participants of each group were provided with verbal and written details regarding the study, including the choice to remove themselves from the study at any time. Written informed consent was obtained from the eventual participants.

The study was conducted in a separate closed room so that the interview would not be interrupted (either in the policlinic room when no patient examination was performed or in the ward manager's room). BD patients' questionnaires were collected by a psychiatric administrative nurse who had experience in the clinic (SE). Healthy controls' questionnaires were collected by a psychiatric nurse who was involved in the study (NEB).

Each interview was conducted face to face and took approximately 20-30 minutes.

\section{Ethical Considerations}

Ethics approval was obtained from the ethics board of the hospital where the study was conducted, and each participant was asked to submit a written informed consent form (No: 51648884).

\section{Statistical Analysis}

SPSS for Windows (SPSS Inc., Chicago, IL, USA) was used for the analysis. In the evaluation of the study data, in addition to descriptive statistical methods (mean, standard deviation, and frequency), chisquared test was used to compare the qualitative data. Significance in the analysis was accepted at $\mathrm{p} \leq 0.05$.

\section{RESULTS}

\section{Sample}

Twenty-six per cent $(n=93)$ of the women with BD included in the study group were in depression, and $74 \%(n=265)$ were in a manic episode. The mean age of the participants in the study group and the control group was similar: the average age of the study group was 36.40 years $(\mathrm{SD}=9.21)$, while the age average of the control group was 35.86 years $(\mathrm{SD}=8.26)$ (Table 1$)$.

\section{Marital Status}

It was determined that in the $\mathrm{BD}$ group, the average marriage age was earlier, the number of married individuals was low, the number of multiple marriages was higher, marital satisfaction was worse, and the

Table 1: Demographic and descriptive characteristics

\begin{tabular}{|c|c|c|c|c|c|c|}
\hline & \multicolumn{2}{|c|}{ Bipolar Disorder $(n=358)$} & \multicolumn{2}{|c|}{ Control $(n=346)$} & \multirow[t]{2}{*}{$\mathbf{t}$} & \multirow[t]{2}{*}{$\mathbf{p}$} \\
\hline & Mean & SD & Mean & SD & & \\
\hline Age & 36.40 & 9.21 & 35.86 & 8.26 & -0.305 & 0.473 \\
\hline \multirow[t]{2}{*}{ Marrying age } & 19.74 & 4.6 & 21.13 & 4.03 & -3.74 & 0.317 \\
\hline & $\mathbf{n}$ & $\%$ & $\mathbf{n}$ & $\%$ & $x^{2}$ & $\mathbf{p}$ \\
\hline \multicolumn{7}{|l|}{ Marital status } \\
\hline Married & 190 & 53.2 & 245 & 70.8 & \multirow{4}{*}{29.50} & \multirow{4}{*}{$p<0.001$} \\
\hline Single & 93 & 26.1 & 66 & 19.1 & & \\
\hline Widowed & 28 & 7.8 & 11 & 3.2 & & \\
\hline Divorced & 46 & 12.9 & 24 & 6.9 & & \\
\hline \multicolumn{7}{|l|}{ Number of marriages } \\
\hline 1 & 226 & 63.8 & 264 & 76.5 & \multirow{3}{*}{18.88} & \multirow{3}{*}{$p<0.001$} \\
\hline 2 & 33 & 9.3 & 14 & 4.1 & & \\
\hline 3 & 5 & 1.4 & 0 & 0 & & \\
\hline \multicolumn{7}{|l|}{ Partner health } \\
\hline Healthy & 224 & 84.5 & 244 & 96.5 & \multirow{3}{*}{21.71} & \multirow{3}{*}{$p<0.001$} \\
\hline Physical disease & 5 & 1.9 & 1 & 0.4 & & \\
\hline Psychiatric disorder & 15 & 5.7 & 2 & 0.8 & & \\
\hline \multicolumn{7}{|l|}{ Marriage Satisfaction } \\
\hline Good/Very good & 147 & 55.9 & 205 & 83 & \multirow{3}{*}{92.64} & \multirow{3}{*}{$p<0.001$} \\
\hline Fair & 42 & 16 & 38 & 15.4 & & \\
\hline Bad/Very bad & 74 & 28.1 & 4 & 1.6 & & \\
\hline
\end{tabular}


Table 2: Menstrual and sexuality characteristics

\begin{tabular}{|c|c|c|c|c|c|c|}
\hline & \multicolumn{2}{|c|}{ Bipolar Disorder $(n=358)$} & \multicolumn{2}{|c|}{ Control $(n=346)$} & \multirow[t]{2}{*}{$\mathbf{t}$} & \multirow[t]{2}{*}{$\mathbf{p}$} \\
\hline & Mean & SD & Mean & SD & & \\
\hline Menarche age & 13.09 & 12.11 & 13.27 & 1.51 & -1.57 & 0.637 \\
\hline Masturbation Frequency (per month) & 8.71 & 13.6 & 2.72 & 1.5 & 4.05 & $<0.001$ \\
\hline \multirow[t]{2}{*}{ Lifetime Sexual Partner number } & 2.06 & 4.58 & 1.18 & 0.67 & 3.19 & $<0.001$ \\
\hline & $\mathbf{n}$ & $\%$ & $\mathbf{n}$ & $\%$ & $\chi^{2}$ & $\mathbf{p}$ \\
\hline \multicolumn{7}{|l|}{ Information about menarche } \\
\hline Yes & 185 & 52.5 & 248 & 71.7 & 36.91 & $<0.001$ \\
\hline \multicolumn{7}{|l|}{ Regular menstruation } \\
\hline Yes & 269 & 77.7 & 313 & 87.4 & 11.51 & $<0.001$ \\
\hline \multicolumn{7}{|l|}{ Dysmenorrhea } \\
\hline Yes & 282 & 78.8 & 223 & 68 & 10.24 & $<0.001$ \\
\hline \multicolumn{7}{|l|}{ Premenstrual Complaints } \\
\hline Edema & 215 & 60.1 & 176 & 53.8 & 2.71 & 0.01 \\
\hline Irritability & 268 & 74.9 & 180 & 55 & 29.65 & $<0.001$ \\
\hline Breast tension & 255 & 71.2 & 197 & 60.2 & 10.44 & 0.005 \\
\hline Hands and feet sweating & 94 & 26.3 & 35 & 10.7 & 27.04 & $<0.001$ \\
\hline Concentration difficulties & 97 & 27.1 & 44 & 13.5 & 19.44 & $<0.001$ \\
\hline Sleep disturbance & 244 & 68.2 & 60 & 18.3 & 171.7 & $<0.001$ \\
\hline Changes in appetite & 173 & 48.3 & 107 & 32.7 & 17.21 & $<0.001$ \\
\hline \multicolumn{7}{|l|}{ Masturbation } \\
\hline Yes & 93 & 26 & 21 & 6.1 & 55.84 & $<0.001$ \\
\hline \multicolumn{7}{|l|}{ Thoughts about masturbation } \\
\hline Positive & 136 & 38 & 98 & 28.3 & & \\
\hline Negative & 212 & 59.2 & 247 & 71.4 & 16.00 & $<0.001$ \\
\hline Neutral & 10 & 2.8 & 1 & 0.3 & & \\
\hline \multicolumn{7}{|c|}{ Having more than one partner at the same time } \\
\hline Yes & 22 & 7.3 & 3 & 1 & 14.22 & $<0.001$ \\
\hline \multicolumn{7}{|l|}{ Sexually transmitted diseases } \\
\hline Yes & 38 & 11.7 & 4 & 1.2 & 31.72 & $<0.001$ \\
\hline \multicolumn{7}{|c|}{$\begin{array}{l}\text { Forced by partner to experiment with different } \\
\text { sexual practices }\end{array}$} \\
\hline Yes & 79 & 23.3 & 16 & 4.6 & 50.01 & $<0.001$ \\
\hline
\end{tabular}

$\chi^{2}$ : chi-squared test, $t$ : Student $t$ test; SD: standard deviation, $p$ : significance was accepted at $p<0.05$

partners were physically or mentally less healthy compared to the control group (Table 1).

\section{Menstrual and Sexuality Characteristics}

No difference was determined between the BD and control groups in terms of menarche age. However; it was determined that the $\mathrm{BD}$ group had no previous knowledge about menarche compared to the control group, did not menstruate regularly, and they experienced more problems such as nervousness, tension in their breasts, sweating at hands and feet, concentration difficulty, sleep disturbance, and changes in appetite before menstruation (Table 2).
It was determined that the members of the $\mathrm{BD}$ group masturbated more, thought more positively of masturbation, had more sexual partners, had more than one partner at the same time, had more sexually transmitted diseases, were forced by their sexual partners to undergo different experiences, and were more exposed to harassment and rape when compared to the control group (Table 2).

\section{Family Planning and the Use of Contraceptives}

There was no difference between the groups in the frequency of using family planning methods; however, withdrawal, which is an ineffective method of 
Table 3: Family planning and use of contraceptives

\begin{tabular}{lccccccc} 
& \multicolumn{2}{c}{ Bipolar Disorder $(\mathbf{n}=\mathbf{3 5 8})$} & \multicolumn{2}{c}{ Control $(\mathbf{n}=\mathbf{3 4 6})$} & & \multicolumn{1}{c}{$\mathbf{p}$} \\
\cline { 2 - 5 } & $\mathbf{n}$ & $\mathbf{\%}$ & $\mathbf{n}$ & $\mathbf{\%}$ & & $\boldsymbol{\chi}^{\mathbf{2}}$ & $\mathbf{p}$ \\
\hline Usage of any contraceptives & 261 & 73.7 & 239 & 69.3 & & 1.70 & 0.111 \\
Oral contraceptive & 49 & 16.8 & 45 & 14.9 & .417 & 2.97 \\
Tubal ligation & 18 & 6.2 & 10 & 3.3 & 2.72 & 0.072 \\
Withdrawal method & 114 & 39.2 & 93 & 30.8 & 4.58 & 0.020 \\
Condom & 75 & 25.8 & 107 & 35.4 & 6.49 & 0.007 \\
Intrauterine contraception device & 63 & 21.6 & 81 & 26.8 & 2.15 & 0.085 \\
Injection & 5 & 1.7 & 2 & 0.7 & 1.41 & 0.210 \\
Calendar method & 2 & 0.7 & 12 & 4 & 6.94 & 0.007 \\
\hline
\end{tabular}

$\chi^{2}$ : chi-squared test, $p$ : significance was accepted at $p \leq 0.05$

contraception, was more common in the study group, while the use of condoms was found to be significantly more frequent in the control group. Furthermore, while the study group obtained information on family planning more from their friends and neighbors, the control group received information from healthcare staff (Table 3).

\section{Pregnancy and Maternal Characteristics}

It was determined that the number of unplanned pregnancies and abortions was higher in the BD group than in the control group. Furthermore, it was determined that the BD group did not attend the checks as regularly during their pregnancy as the members of the control group; they smoked more during pregnancy and in the postpartum period, were exposed to more violence during pregnancy, and breastfed their babies less (Table 4).

\section{Gynecological Characteristics}

It was determined that the $\mathrm{BD}$ group did not undertake self-examination for control purposes as regularly as the control group in terms of gynecological characteristics, did not have mammograms taken, did not go for gynecological examination, did not have a pap smear and suffered more from urinary incontinence problems (Table 5). The menopausal age was $45.16 \pm 4.61$ for women with $\mathrm{BD}$ and $45.44 \pm 4.12$ for the control group. No difference in menopausal age was determined between the study group and the control group ( $\mathrm{t}$ : $-0.305 ; \mathrm{p}=0.473)$.

\section{DISCUSSION}

BD frequently starts during adolescence or young adulthood, which is a sexually active and fertile period, and the chronic process of the disease may affect women's reproductive and sexual lives. However, the necessary importance is not given to the reproductive and sexual health of women with $\mathrm{BD}$ both in clinical practice and in the literature (5). Studies on the reproductive and sexual health of psychiatric patients were conducted with individuals suffering from a variety serious psychiatric disorders. However, each psychiatric disorder has its own different reproductive and sexual health risks. In this case, studies that address the risks specific to the disease are of particular importance. In this study, we assessed the reproductive and sexual health problems of women with $\mathrm{BD}$ in comparison with healthy controls.

The effect of the menstrual cycle on the course of $\mathrm{BD}$ is uncertain. While some studies show that women with BD show a worsening mood in the premenstrual period and menstrual problems (9-11), other studies assert the contrary $(3,4)$. In our study, menstrual complaints and dysmenorrhea were observed at a higher rate among women with BD (BD: 78.8\%; control group: 21.2\%). Most of the existing literature is either based on the physiological assessment of individual cases (for example, serum steroid levels) or includes follow-ups for insufficient periods of time in order to examine the relationship between them. More detailed studies of different types are required in order to understand the relationship between menstrual cycle and $\mathrm{BD}$.

A great majority (64\%) of the case presentation studies in a systematic review assessing the effects of $\mathrm{BD}$ on the menstrual cycle reported that hypomanic or manic attacks develop in women with $\mathrm{BD}$ in the premenstrual period. Again, in the same systematic review, mood swings in the menstrual cycle were reported to occur in between 64 and $68 \%$ of cases in retrospective studies conducted with women suffering from $\mathrm{BD}$, and while premenstrual dysphoric disorder was reported in between 15 and $27 \%$ of cases, mood 
Table 4: Pregnancy and maternal characteristics

\begin{tabular}{|c|c|c|c|c|c|c|}
\hline & \multicolumn{2}{|c|}{ Bipolar Disorder $(n=358)$} & \multicolumn{2}{|c|}{ Control $(n=346)$} & \multirow[b]{2}{*}{$\mathbf{t}$} & \multirow[b]{2}{*}{$\mathbf{p}$} \\
\hline & Mean & SD & Mean & SD & & \\
\hline Unplanned pregnancy & 1.64 & 2.59 & 0.48 & 0.98 & 6.68 & $<0.001$ \\
\hline Planned pregnancy & 1.71 & 1.44 & 2.23 & 1.34 & -4.27 & $<0.001$ \\
\hline Dilatation and curettage & 0.90 & 1.83 & 0.04 & 0.23 & 7.44 & $<0.001$ \\
\hline \multirow[t]{2}{*}{ Duration of breastfeeding } & 12.86 & 12.20 & 10.90 & 7.31 & 1.86 & $<0.001$ \\
\hline & $\mathbf{n}$ & $\%$ & $\mathbf{n}$ & $\%$ & $\chi^{2}$ & $\mathbf{p}$ \\
\hline \multicolumn{7}{|l|}{ Take control during pregnancy } \\
\hline Never & 66 & 26.1 & 28 & 10.9 & & \\
\hline Occasionally & 60 & 23.7 & 49 & 19.1 & 25.29 & $<0.001$ \\
\hline Regularly & 127 & 50.2 & 179 & 69.6 & & \\
\hline Smoking in pregnancy and puerperium & 70 & 27.7 & 42 & 16.4 & 9.40 & $<0.001$ \\
\hline Exposure to violence during pregnancy & 113 & 44.7 & 34 & 13.3 & 61.01 & $<0.001$ \\
\hline \multicolumn{7}{|l|}{ Type of violence during pregnancy } \\
\hline Physical & 54 & 47.8 & 7 & 20.6 & & \\
\hline Verbal & 14 & 12.4 & 10 & 29.4 & 13.77 & 0.008 \\
\hline Sexual & 5 & 4.4 & 0 & 0 & & \\
\hline Breastfeeding status & 118 & 80.8 & 233 & 98.3 & 36.09 & $<0.001$ \\
\hline
\end{tabular}

$\chi^{2}$ : chi-squared test, t: Student t test, SD: standard deviation, $p$ : significance was accepted at $p<0.05$

Table 5: Gynecological characteristics

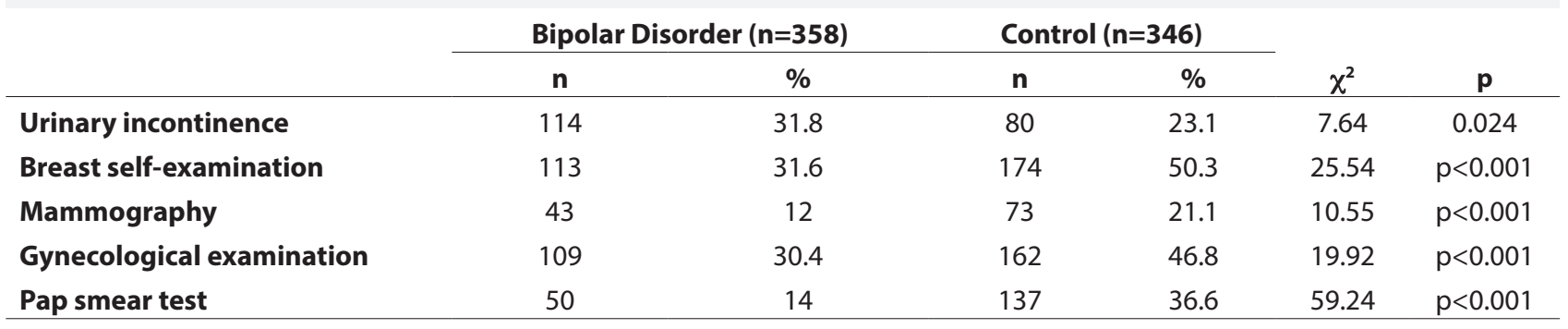

$\chi^{2}$ : chi-squared test, $\mathrm{p}$ : significance was accepted at $\mathrm{p}<0.05$

swings were reported in between 44 and $65 \%$ in prospective studies (11). Contrary to their findings, Karadag et al. (3) compared 34 women with BD with the control group, and while they did not find any difference in terms of menarche, cycle order, and menorrhea, they determined that the control group had more complaints such as nervousness, anger, anxiety, body edema, emotional changes, and social inhibition during the premenstrual period. It was argued that the surprising result in this study may be due to the protective effect of the long-term $\mathrm{BD}$ treatment in premenstrual complaints (4) No difference was determined between the groups in terms of menarche age in our study, which is consistent with the literature $(9,12)$.

Studies show that unsafe sex practices are prevalent among women with $\mathrm{BD}(1,5,7,13-15)$. On the other hand, patients with $\mathrm{BD}$ also differ between themselves with regard to their mood characteristics. It is reported that patients in the manic episode have more sexual partners and sex with strangers without the use of condoms than healthy controls as a result of libido increase, cognitive impairment, and alcohol or substance use (14). Their sex life may become passive in the depressive episodes of the disorder. Given that the same clinical diagnosis includes different episodes, different clinical approaches are required in terms of the patients' sexual and reproductive health. However, in the retrospective investigation of the reproductive and sexual health of these patients, problems that seem to be at opposite ends are assessed cumulatively, as both types of episodes have been experienced in the past. Hence, unsafe sex $(1,5,7,15)$, STDs $(5,6)$ and the less consistent use of family planning methods $(1,5,7,15)$, which are mostly among the results of the deterioration 
in manic episode-specific impulse control, are serious sexual health problems for all women with $\mathrm{BD}$. In this context, our finding that the study group has more sexual partners compared to the control group, experiences more STDs, and uses family planning methods less conforms to the literature.

Women with $\mathrm{BD}$ are at a high risk of unwanted pregnancies as a result of exhibiting sexually risky behaviors that are related to mania, not using any contraception, or using ineffective methods (7). In such cases, in addition to the behavioral effects of the psychiatric disorder on women, state policies on reproductive health and the cultural structure are also of great importance. While it is seen that the most effective methods such as tube ligation and quarterly injection are preferred in certain studies (7), it is remarkable that methods that are hard to use for women with $\mathrm{BD}$, such as the use of oral drugs, are preferred in certain studies (6). In this study, it was determined that women with BD use ineffective contraceptive methods such as withdrawal more often. Unplanned pregnancies are problematic in that they create potentially serious consequences for women, their children, family, and the health system (5). Marengo et al. reported that only one in every 3 women with $\mathrm{BD}$ has planned pregnancies, while this rate is approximately $80 \%$ in the healthy group (5). In a study carried out in adolescents with BD in the USA, Heffner et al. (16) found that $30 \%$ of the participants had experienced an unplanned pregnancy. The finding that unsafe sex and the use of ineffective family planning actually contribute to more unwanted pregnancies in the study group than in the control group is another striking point in our study.

Pregnancy and the postpartum period are challenging times in a woman's life. Women with BD have a particularly hard time in this period due to hormonal changes and the risk of a relapse of the disease is substantial. Problems such as the interruption of drug use in the pregnancy period, the teratogenic effect of the drugs used, baby care in the postpartum period, and a decrease in the rate of breastfeeding can be observed, and this may affect the life of both the mother and the baby significantly (17-21). In Turkey, almost all women (97\%) receive prenatal care and breastfeed their children (96\%) (22). It is estimated that some of the women who do not receive prenatal care, approximately $3 \%$, are individuals with serious psychiatric diseases. Annagur et al. (1) report that 10\% of women with BD do not receive sufficient prenatal care due to the disorder and $21.6 \%$ cannot breastfeed their babies as they suffer attacks or use drugs. In our study, the finding that women in the study group receive less prenatal care and breastfeed less when compared to the control group is supported by the results of other studies in the literature (8,23-25).

Changing female roles during pregnancy and the postpartum period and the ensuing pressures make it hard for women to cope and sometimes push them towards harmful habits such as smoking. Smoking during pregnancy affects the health of the fetus in the uterus and causes complications such as low birth weight and stillbirth. It has been reported that children of women who are smoking during their pregnancy have attention deficit problems in childhood, which are followed by disruptive behavioral problems in adolescence, and then a high rate of substance use and anti-social behaviors (26). In a study by Caleyachetty et al. (27) involving 54 countries, the rate of smoking during pregnancy was found to be $2.6 \%$. In their study, the smoking rate of pregnant women living in countries with a low and middle-income level was found to be lower, while it was found to be high in middle-income countries and $15 \%$ for Turkey, where the present study was carried out. According to the data of the Survey of Population and Health in Turkey 2008, $11 \%$ of pregnant women and $17 \%$ of breastfeeding women in this country smoke (28). This rate increases to $23 \%$ (29) or $24.6 \%$ in women with psychiatric disorders (8). In our study, cigarette use during pregnancy and the postpartum period in women with $\mathrm{BD}$ in the study group was found to be higher than in the control group.

There are only few studies that examine violence in psychiatric patients compared to violence studies carried out in other populations. However, in the limited number of studies that have been done, the rate of exposure to violence in psychiatric patients is $30-60 \%$, whic was higher than in the general population $(8,29)$. In the systematic review by Volavka $(30)$ examining violence experienced by bipolar and schizophrenia patients, it is clearly seen that these patients are exposed to more violence than the general population. The risk for patients with $\mathrm{BD}$ to experience violence is higher than in schizophrenia patients, and the exposure to violence generally occurs during the manic phase. Furthermore, the rate of exposure to violence increases in bipolar and schizophrenia patients if comorbid substance abuse is present (30). Trevillion et al. (31), comparing the violence experienced by women with $\mathrm{BD}$ and men in the USA, reported that women are exposed to lifetime violence approximately 4 times more than men $(26.7 \%$ in women; $7.1 \%$ in 
men). Another study performed on women with BD found physical violence in $36 \%$ and sexual violence $43.4 \%$, while these rates were $30.8 \%$ for physical violence and $21.2 \%$ for sexual violence among men (32). We found no study regarding the violence experienced by women with $\mathrm{BD}$ during pregnancy.

Menopause is a significant life event for women who have a psychiatric disorder. Approximately $30 \%$ of women with psychiatric disorders have indicated that there is an increase in the symptoms of the psychiatric disorder during the menopause period (33). In one study, menopausal symptoms were observed 1.69 times more in women with $\mathrm{BD}$ and the menopausal age in psychiatric patients was reported to be 51.3 (34). While the menopausal age is between 45 and 55 years globally, it has been reported to be between 45 and 47 years in Turkey $(35,36)$. The menopausal age in our study results (BD: $45.16 \pm 4.61$ years; control group: $45.44 \pm 4.12$ years) is consistent with the literature, and no difference was determined between the study group and the control group.

Individuals with serious mental disorders are regarded to be a vulnerable group at risk of developing cancer due to various factors such as smoking, poor lifestyle, lack of exercise, poor nutrition, and benefiting less from healthcare services. In previous studies, breast cancer, lung cancer, and colorectal cancer risk and cancer incidence were determined to be higher in psychiatric patients than in the general population (37). In a study done in the USA, lung cancer was observed 4.9 times, colorectal cancer 4.1 times, and breast cancer 1.9 times more often in women with $\mathrm{BD}$ than in the general population according to a standardized incidence rate (38). Our finding that these women undergo less cancer screening although they are at a higher risk is consistent with the literature (37). It was considered that this is related to the low educational levels of psychiatric patients.

The present study have some limitations. The BD status was not recorded in detail in the study (such as type of the disorder, number of episodes, age at onset of the disease, comorbid substance use history). Another limitation is the fact that our study was cross-sectional, not a long-term follow-up study, and was carried out at a single center. Furthermore, the reproductive and sexual characteristics of the patients were investigated verbally without a valid and reliable scale (as there is no psychometrically standardized scale available) and could not be assessed by the clinician (e.g., no lab tests for STDs were used). This may cause overreporting. Another limitation of our study was that we did not exclude the diagnostic subgroups of Axis II diagnoses of patients. Axis II diseases are thought to change the reproductive and sexual health outcomes of patients. In this study, the control group consisted of participants who, according to their own self-reporting, had no psychiatric disorders. We did not administer a standardized test such as SCID to identify possible psychiatric disorders, which is a further limitation of our study.

It was found that women with $\mathrm{BD}$ have more premenstrual complaints and irregular menstruation and may have more than one sexual partner at the same time. In line with this observation, it was determined that the numbers of unplanned pregnancies and STDs in women with $\mathrm{BD}$ are higher. Furthermore, according to the results of our study, it was found that women with $\mathrm{BD}$ use contraceptive methods less frequently and pay less attention to important issues of women's health such as gynecological examinations, breast selfexamination, and pap smear.

It should be noted that women with $\mathrm{BD}$ need to be informed more about these issues in clinical practice. Multi-dimensional studies that examine the social functionality of BD by its types and especially the effects of the disorder and drugs on fertility are required in the future.

The present study also have some strengths. This study allowed us to get information by comparing the reproductive and sexual health characteristics of women with BD with a control group. Our study is important both in that it was carried out with a large sample group at the largest mental health hospital in Turkey and because it gives the opportunity to compare the patients with a control group.

\begin{tabular}{|c|c|c|}
\hline \multicolumn{2}{|c|}{ Contribution Categories } & \multirow{2}{*}{$\begin{array}{l}\text { Author Initials } \\
\text { H.D., N.E.B., N.K.O., S.E. }\end{array}$} \\
\hline \multirow{3}{*}{ Category 1} & Concept/Design & \\
\hline & Data acquisition & S.E., H.D., N.E.B., N.K.O. \\
\hline & Data analysis/Interpretation & N.K.O., H.D., N.E.B., S.E. \\
\hline \multirow{2}{*}{ Category 2} & Drafting manuscript & H.D., N.E.B., N.K.O., S.E. \\
\hline & Critical revision of manuscript & H.D., N.E.B., N.K.O., S.E. \\
\hline Category 3 & Final approval and accountability & H.D., N.E.B., N.K.O., S.E. \\
\hline \multirow{2}{*}{ Other } & Technical or material support & $\mathrm{N} / \mathrm{A}$ \\
\hline & Supervision & $\mathrm{N} / \mathrm{A}$ \\
\hline
\end{tabular}

Ethics Committee Approval: The study was approved by the Local Ethics Committee.

Informed Consent: Written informed consent was obtained from the patient for the publication of the case report and the accompanying images.

Peer-review: Externally peer-reviewed. 
Conflict of Interest: None declared.

Financial Disclosure: None declared.

\section{REFERENCES}

1. Annagur BB, Zincir SB, Bez Y, Inanli I, Sahingoz M, Ates N, Alpak G. Social and reproductive lives of women with bipolar disorder: A descriptive study from Turkey. Journal of Mood Disorders 2013; 3:11-16. (Turkish)

2. Ozerdem A, Rasgon N. Women with bipolar disorder: a lifetime challenge from diagnosis to treatment. Bipolar Disord 2014; $16: 1-4$.

3. Karadag F, Akdeniz F, Erten E, Pirildar S, Yucel B, Polat A, Atmaca M. Menstrually related symptom changes in women with treatment-responsive bipolar disorder. Bipolar Disord 2004; 6:253-259.

4. Reynolds-May MF, Kenna HA, Marsh W, Stemmle PG, Wang P, Ketter TA, Rasgon NL. Evaluation of reproductive function in women treated for bipolar disorder compared to healthy controls. Bipolar Disord 2014; 16:37-47.

5. Marengo E, Martino DJ, Igoa A, Scapola M, Fassi G, Baamonde MU, Strejilevich SA. Unplanned pregnancies and reproductive health among women with bipolar disorder. J Affect Disord 2015; 178:201-205.

6. Magalhaes PV, Kapczinski F, Kauer-Sant'Anna M. Use of contraceptive methods among women treated for bipolar disorder. Arch Womens Ment Health 2009; 12:183-185.

7. Berenson $\mathrm{AB}$, Asem H, Tan A, Wilkinson GS. Continuation rates and complications of intrauterine contraception in women diagnosed with bipolar disorder. Obstet Gynecol 2011; 118:13311336.

8. Ozcan NK, Boyacioglu NE, Enginkaya S, Dinc H, Bilgin H. Reproductive health in women with serious mental illnesses. J Clin Nurs 2014; 23:1283-1291.

9. Aldemir E, Akdeniz F, Isikli S, Bilen NK, Vahip S. Reproductive and sexual functions in bipolar patients: Data from a specialized mood disorder clinic. Dusunen Adam 2016; 29:67-75.

10. Robakis TK, Holtzman J, Stemmle PG, Reynolds-May MF, Kenna HA, Rasgon NL. Lamotrigine and GABA A receptor modulators interact with menstrual cycle phase and oral contraceptives to regulate mood in women with bipolar disorder. J Affect Disord 2015; 175:108-115.

11. Teatero ML, Mazmanian D, Sharma V. Effects of the menstrual cycle on bipolar disorder. Bipolar Disord 2014; 16:22-36.

12. Sit D, Seltman H, Wisner KL. Menstrual effects on mood symptoms in treated women with bipolar disorder. Bipolar Disord 2011; 13:310-317.

13. Mazza M, Harnic D, Catalano V, Di Nicola M, Bruschi A, Bria P, Daniele A, Mazza S. Sexual behavior in women with bipolar disorder. J Affect Disord 2011; 131:364-367.

14. Downey J, Friedman RC, Haase E, Goldenberg D, Bell R, Edsall S. Comparison of sexual experience and behavior between bipolar outpatients and outpatients without mood disorders. Psychiatry J 2016; 5839181:1-10.
15. Pagano HP, Zapata LB, Berry-Bibee EN, Nanda K, Curtis KM. Safety of hormonal contraception and intrauterine devices among women with depressive and bipolar disorders: a systematic review. Contraception 2016; 94:641-649.

16. Heffner JL, DelBello MP, Fleck DE, Adler CM, Strakowski SM. Unplanned pregnancies in adolescents with bipolar disorder. Am J Psychiatry 2012; 169:1319-1329.

17. Kieviet N, Dolman KM, Honig A. The use of psychotropic medication during pregnancy: How about the newborn. Neuropsychiatr Dis Treat 2013; 9:1257-1266.

18. Jones I, Chandra PS, Dazzan P, Howard LM. Bipolar disorder, affective psychosis, and schizophrenia in pregnancy and the post-partum period. Lancet 2014; 384:1789-1799.

19. Petersen I, McCrea RL, Osborn DJ, Evans S, Pinfold V, Cowen PJ, Gilbert R, Nazareth I. Discontinuation of antipsychotic medication in pregnancy: A cohort study. Schizophr Res 2014; 159:218-225.

20. Taylor CL, Stewart R, Ogden J, Broadbent M, Pasupathy D, Howard LM. The characteristics and health needs of pregnant women with schizophrenia compared with bipolar disorder and affective psychoses. BMC Psychiatry 2015; 15:1-10.

21. Spigset O, Nordeng H. Safety of Psychotropic Drugs in Pregnancy and Breastfeeding: In Spina E, Trifiro G (editors). Pharmacovigilance in Psychiatry. Cham: Adis (Springer International Publishing), 2016, 299-319.

22. Hacettepe University, Institute for Population Studies. Survey of Population and Health in Turkey 2013. Ankara: Hacettepe University, Institute for Population Studies, Turkish Ministry for Development, and TUBITAK, 2014. http://www.hips.hacettepe. edu.tr/tnsa2013/rapor/TNSA_2013_ana_rapor.pdf. Accessed Oct. 23, 2017. (Turkish)

23. Klinger G, Stahl B, Fusar-Poli P, Merlob P. Antipsychotic drugs and breastfeeding. Pediatr Endocrinol Rev 2013; 10:308-317.

24. Pope CJ, Sharma V, Mazmanian D. Bipolar disorder in the postpartum period: management strategies and future directions. Womens Health (Lond) 2014; 10:359-371.

25. Broeks SC, Horsdal HT, Ingstrup KG, Gasse C. Psychopharmacological drug utilization patterns in pregnant women with bipolar disorder - A nationwide register-based study. J Affect Disord 2017; 210:158-165.

26. Talati A, Bao Y, Kaufman J, Shen L, Schaefer CA, Brown AS. Maternal smoking during pregnancy and bipolar disorder in offspring. Am J Psychiatry 2013; 170:1178-1185.

27. Caleyachetty R, Tait CA, Kengne AP, Corvalan C, Uauy R, $\mathrm{O}$-Tcheugui JBE. Tobacco use in pregnant women: analysis of data from demographic and health surveys from 54 low-income and middle-income countries. Lancet Glob Health 2014; 2:513520.

28. Hacettepe University, Institute for Population Studies. Survey of Population and Health in Turkey 2008. Ankara: Hacettepe University, Institute for Population Studies, Ministry for Health Mother and Child Health and Family Planning Directorate General, Prime Minister's Office State Planning Organization Undersecretariate, 2009. Retrieval Date: 23.10.2017, http:// 
www.hips.hacettepe.edu.tr/TNSA2008-AnaRapor.pdf. Accessed October 23, 2017. (Turkish)

29. Howard LM, Bekele D, Rowe M, Demilew J, Bewley S, Marteau TM. Smoking cessation in pregnant women with mental disorders: a cohort and nested qualitative study. BJOG 2013; 120:362-370

30. Volavka J. Violence in schizophrenia and bipolar disorder. Psychiatr Danub 2013; 25:24-33.

31. Trevillion K, Oram S, Feder G, Howard LM. Experiences of domestic violence and mental disorders: a systematic review and meta-analysis. PloS One 2012; 7:e51740.

32. Leverich GS, McElroy SL, Suppes T, Keck PE, Jr Denicoff KD, Nolen WA, Altshuler LL, Rush AJ, Kupka R, Frye MA, Autio KA, Post RM. Early physical and sexual abuse associated with an adverse course of bipolar illness. Biol Psychiatry 2002; 51:288-297.

33. Sajatovic M, Rosenthal MB, Plax MS, Meyer ML, Bingham CR. Mental illness and menopause: a patient and family perspective. J Gend Specif Med 2003; 6:31-34.
34. Hu LY, Shen CC, Hung JH, Chen PM, Wen CH, Chiang YY, Lu T. Risk of psychiatric disorders following symptomatic menopausal transition: A nationwide population-based retrospective cohort study. Medicine (Baltimore) 2016; 95:1-7.

35. Amore M, Donato PD, Berti A, Palareti A, Chirico C, Papalini A, Zucchini S. Sexual and psychological symptoms in the climacteric years. Maturitas 2006; 56:303-311.

36. Sahin NH, Coskun A. The menopausal age, related factors and climacteric, complaints in Turkish women. Revista Referencia 2007; 2:91-99.

37. Mo PK, Mak WWS, Chong ESK, Shen H, Cheung RYM. The prevalence and factors for cancer screening behavior among people with severe mental illness in Hong Kong. PloS One 2014; 9:1-11.

38. McGinty EE, Zhang Y, Guallar E, Ford DE, Steinwachs D, Dixon LB, Keating N, Daumit GL. Cancer incidence in a sample of Maryland residents with serious mental illness. Psychiatr Serv 2012; 63:714-717. 